\title{
Innovating for lowcarbon energy through hydropower: Enabling a conservation charity's transition to a lowcarbon community
}

Gallagher, John; Coughlan, Paul; Williams, Arwel; McNabola, Aonghus

\section{Creativity and innovation management}

DOI:

10.1111/caim. 12291

Published: 01/12/2018

Peer reviewed version

Cyswllt i'r cyhoeddiad / Link to publication

Dyfyniad o'r fersiwn a gyhoeddwyd / Citation for published version (APA):

Gallagher, J., Coughlan, P., Williams, A., \& McNabola, A. (2018). Innovating for lowcarbon energy through hydropower: Enabling a conservation charity's transition to a lowcarbon community. Creativity and innovation management, 27(4), 375-386.

https://doi.org/10.1111/caim.12291

\footnotetext{
Hawliau Cyffredinol / General rights

Copyright and moral rights for the publications made accessible in the public portal are retained by the authors and/or other copyright owners and it is a condition of accessing publications that users recognise and abide by the legal requirements associated with these rights.

- Users may download and print one copy of any publication from the public portal for the purpose of private study or research.

- You may not further distribute the material or use it for any profit-making activity or commercial gain

- You may freely distribute the URL identifying the publication in the public portal ?
}

Take down policy

If you believe that this document breaches copyright please contact us providing details, and we will remove access to the work immediately and investigate your claim. 


\title{
Innovating for low-carbon energy through hydropower: Enabling a conservation charity's transition to a low-carbon community
}

\begin{abstract}
For an organisation to become a low-carbon community, delivering a range of sustainability initiatives is necessary. Renewable energy (RE) initiatives offering a source of low-carbon electricity to offset an organisation's energy needs, fit with this objective. This paper examines the role of innovation in achieving low-carbon energy in the National Trust (NT), a conservation charity and the largest landowner in the UK. It considers how an eco-design approach to delivering innovative RE projects, specifically hydropower (HP) installations, has supported their transition to a low-carbon community. Three HP projects delivered on time and within budget were examined; support for each was built through transparent and regular communications with the NT's membership. Despite limited resources and funding for innovation, the NT minimised the associated risk through effective management and external collaboration. It fostered an open environment for creativity and idea sharing, which was key to delivering the RE projects. Innovation was particularly evident in the HP initiatives explored, as eco-design considerations informed new and innovative design choices and technology selection as each HP project was designed and constructed. Transitioning to a low-carbon community is an achievable reality for a conservation charity, and this is enabled through the management of innovation to deliver solutions that meet the low-carbon energy challenge.
\end{abstract}

Keywords: renewable energy; hydropower; innovation audit; low-carbon community; ecodesign.

\section{INTRODUCTION}

The push to achieve a low-carbon society and to reduce greenhouse gas (GHG) emissions is driven by recent international agreements such as COP21 (UNFCCC, 2015). However, the success of sustainability initiatives is dependent on stakeholder engagement and support from the bottom-up or at a local level (Zhang et al., 2013, Middlemiss and Parrish, 2010). Providing evidence of local learning is key to successful low-carbon community success stories (Heiskanen et al., 2015). This paper explores the primary question: how has a systematic approach to the management of innovation aided in the delivery of low-carbon energy through renewable energy (RE) projects? The corresponding purpose is to explore the role of innovation in transitioning to a low-carbon community. Taking a case study approach, we explore how a charity managed a programme of investment in innovation in renewable energy to generate low-carbon electricity.

Renewable energy (RE) is central to the global response to climate change and a sustainable future (Reilly, 2013). As a sustainability initiative, RE can aid the production of low-carbon energy and reduce GHG emissions. The potential for RE to support a low-carbon society on a global scale is reflected in a recent IRENA (2016) roadmap report. At a national level and enabled by national energy policy frameworks, the UK has tripled the contribution of RE to electricity demands in recent years (DECC, 2016). A top-down approach addressing lowcarbon sustainability in China has led to a 5\% reduction in energy consumption (Jiang et al., 2013). At an organisational level, some organisations have put sustainable development plans in place to achieve low-carbon energy and help reduce energy future demands (NT, 2014b). 
Hydropower (HP) is the most mature form of RE and generates $16 \%$ of current global electricity demands (REN21, 2014). It is a key RE source to achieve long-term low-carbon energy and to help meet GHG emission targets (Kumar et al., 2011). Most large-scale HP projects have been exploited in the developed world and attention has now focused on small and micro-scale installations (EUREC, 2009). There is significant potential for increased capacity at these scales (IEA, 2012), with Bódis et al. (2014) highlighting 28,000 unexploited sites in Europe alone, equating to $7.35 \mathrm{TWh}$ of electricity generation and potentially offsetting 2.96 Mt of $\mathrm{CO}_{2}$ emissions (Gallagher et al., 2015). However, the same study identified opportunities to adopt low-carbon design to reduce the environmental impacts of developing these projects through the adoption of eco-design. The combination of technological advancements, savings from lean product manufacturing and government incentivisation are some of the key factors that have driven continued investment in the sector (IRENA, 2015).

Previous research has demonstrated the higher material contribution in RE technologies in comparison to conventional fossil fuel generation systems (Hertwich et al., 2015, Kleijn et al., 2011), therefore consider alternative materials and design can improve the performance of these low-carbon technologies. The application of eco-design, driven by the EC Directive 2009/125/EC (EC, 2009), can support this goal to reduce resource demands and the attributed environmental impacts by considering the 'anthropogenic and ecological values' in the early stages of the design process (Shu-Yang et al., 2004). Eco-design challenges the integration of economic cost and environmental impact perspectives during the product development process and throughout its life cycle, thus benefiting the viability of RE technologies. Ecodesign is an important step in the transition to a circular economy (EC, 2015), as Gallagher et al. (2018) identify its role for enhancing the environmental performance of RE technology over several iterations of a systems life cycle.

The successful implementation of RE is also dependent on changing community behaviour and practices (Moloney et al., 2010, Jiang et al., 2013). It is this challenge which is at the heart of this paper. The establishment of a conservation land ownership movement predates today's interest in low-carbon communities (Croft, 2004). Charitable donations have influenced the ability of voluntary bodies to acquire land, some with a specific focus on trees and wild land with others focused on outdoor recreation. In this way, volunteers are central to environmental preservation: "The work of conservation volunteers has reflected the environmental concerns over the years focusing on the management of nature reserves in the 1960s, the response to changes brought about by modern agricultural techniques in the 1970 s, the protection of the urban environment in the 1980s and...in the 1990s, the need to integrate economic, environmental and social issues, especially at the local level" (Turner et al., 2001).

\section{INNOVATING IN A SYSTEMATIC WAY}

A systematic approach to innovation in the water-energy sector has a critical role in deploying economically viable technology (Gebauer and Saul, 2014). Where HP projects are a key part of an organisation's sustainability programme, managing innovation can help achieve success within economic constraints (Molle et al., 2005). So, what do we understand from previous research as a systematic approach to innovation? First, we define briefly the scope of innovation management before exploring the challenges of design driven open innovation and systematic design methods. 


\section{Innovation management}

Rogers (1995) defined an innovation as "an idea, a product or process, system or device that is perceived to be new to an individual, a group of people or firms, an industrial sector or a society as a whole". Viewing innovation as a process has the potential both to provide a framework for helping managers to assess, benchmark and improve this area (Chiesa et al., 1996). As a process, innovation can be managed both strategically and operationally. Strategic innovation occurs when a company "identifies gaps in the industry positioning map, decides to fill them, and the gaps grow to become the new mass market" (Markides, 1997). Operationally, innovation requires the management of technical, design, manufacturing, management and commercial activities involved in realising a new or improved product, manufacturing process or equipment (Freeman, 1994). Yet, it is important to consider how the process of innovation management is measured to ensure a fair comparison of performance and generating relevant benchmarks (Adams et al., 2006).

The management of innovation can be explored within the strategic niche management space, as innovation can evolve over time and can be co-developed between stakeholders (Schot and Geels, 2008). Within such a characterisation of innovation, and considering the approach of strategic niche management, there are many choices and emphases open to managers in organisations. Three merit consideration here: to engage in open or closed innovation; to be pulled by user requirements or to be pushed by a vision about possible product meanings; to be systematic in design.

\section{Open Innovation}

"To understand the principles of open innovation, it is important first to know the fundamentals of closed innovation" (Grönlund et al., 2010). In a closed innovation model, the innovation process takes place within the firm. In contrast, in the open model, both inteRernal and external ideas and capabilities are of use (Chesbrough, 2003). The main benefits of open innovation include an opportunity to create a more innovative culture through continued exposure and relationships with external innovators (Docherty, 2006, Grönlund et al., 2010). Here, though, Ollila and Elmquist (2011) identified managerial challenges associated with open innovation at the interface among partner organisations, in relation to the motivation for collaboration among the partner organizations and to collaboration within teams. They link their empirical insights to collaborative innovation, "where several stakeholders with different cultures, structures and management systems join forces in activities related to strategic innovation".

\section{Design driven innovation}

In his seminal piece, Verganti (2008) distinguishes between market-pull, technology-push and design-driven innovation. He defines design-driven innovation as "pushed by a firm's vision about possible new product meanings and languages that could diffuse in society". In design-driven innovation, the innovation starts "from the comprehension of subtle and unspoken dynamics in sociocultural models and results in proposing radically new meanings and languages that often imply a change in sociocultural regimes". To manage such an innovation approach requires a capability to understand, anticipate, propose, and influence the emergence of new meanings in conjunction with a distributed network of actors. The 
process is networked, extends beyond the firm boundaries, is based on knowledge sharing and includes action to influence the sociocultural regime.

There is evidence of design-driven innovation with the adoption of eco-design considerations to deliver sustainable products and services in SMEs (Klewitz and Hansen, 2014) with the rise of new business models that consider climate change and other key environmental challenges at the core of their organisation (Jabbour et al., 2015). Furthermore, eco-design is evident in companies that are driven be innovation, as it is fundamental in technology development and operations of businesses in the future (Santolaria et al., 2011).

\section{Systematic design}

Increasingly, today's innovation process uses structured approaches including structured design methods (Fernandes et al., 2009). Leenders et al. (2007) characterised systematic design methods according to four underlying principles: hierarchical decomposition, systematic variation, satisficing, and discursiveness. They noted that "The principles have evolved through their effectiveness in solving NPD problems by NPD professionals and NPD teams and form the basis of the integrated techniques that are common today". From their study, they suggested that that systematic design methods "should be most useful for situations in which moderate levels of team creativity are required".

\section{Conclusion and proposed framework}

The review of selected literature on innovation management suggests that the use of open innovation, design-driven innovation and systematic design methods are relevant to innovation-based performance. To guide our exploration of how a systematic approach to the management of innovation impacted a conservation charity in its transition to a low-carbon community, a theoretical framework is presented in Figure 1. This framework is based upon the conceptualisation by Rip (2012) of a multi-level model of 'niches' as technological developments, 'socio-technical regimes' as rules for further technology development, and 'landscapes' as a context of opportunities and constraints. Here, the niche is the low-carbon energy projects, in the form of RE installations, undertaken by the conservation charity within which innovation takes place. Technological niche development is only considered to succeed where stakeholders invest time into nurturing an innovation, and the iterative development of RE projects within an organisational structure with rules can provide a platform for learning and improvements (Schot and Geels, 2007). The use of open innovation, design-driven innovation and systematic design methods conservation charity represents the regime through which the innovation journey is undertaken. Here, eco-design is a form of design driven innovation, but it requires the space for ideas to emerge from stakeholder collaboration over time. Finally, the landscape of the low-carbon is 'the slowly changing backdrop against which interactions are played out' (Rip, 2012) and includes concerns for renewable and low-carbon energy, energy efficiency and recycling/re-use of resources as the conservation charity transitions to a low-carbon community.

\section{RESEARCH DESIGN}

This paper explores the primary question: how has a systematic approach to the management of innovation aided in the delivery of low-carbon energy through RE projects? The corresponding purpose is to explore the role of innovation in transitioning to a low-carbon 
community. To explore the primary question, case research is undertaken to capture the approach to achieving sustainability goals and a low-carbon community.

Case studies can be used for different types of research purpose such as exploration, theory building, theory testing and theory extension/refinement (Voss, 2009). Leonard-Barton (1990) describes a case study as "a history of a past or current phenomenon, drawn from multiple sources of evidence. It can include data from direct observation and systematic interviewing as well as from public and private archives. In fact, any fact relevant to the stream of events describing the phenomenon is a potential datum in a case study, since context is important". A suitable case organisation for an in-depth low-carbon energy case study has an agenda for low-carbon energy and embraces RE projects to achieve its goal.

The National Trust (NT), a conservation charity, was selected as an organisation where this challenge was particularly relevant and from which much could be learned. "The origins of the land owning conservation charity in Britain arguably start with the National Trust, established in London in 1895, with powers to hold land throughout the British Isles" (Croft, 2004). The NT met the criteria for an organisation that was actively implementing new technologies and strategies to achieve low-carbon energy and a low-carbon future. Its plan was to consider climate change in all of its decisions, through management plans from a micro to a macro level (NT, 2014a). In 2013, the NT launched a $£ 3.5$ million pilot Renewable Energy Investment (REI) Programme to develop five RE projects, including HP installations. Due to the success of the programme, a more ambitious plan was put in place in 2015 with $£ 30$ million committed for investment to deliver $60 \mathrm{RE}$ projects, predominantly renewable heat and HP (NT, 2015a). This evolution demonstrates a commitment to transitioning to a low-carbon community.

\section{DATA COLLECTION}

In this paper, an in-depth case study is developed. The starting point is the research question and framework. The exploration of the approach to the management of innovation merits consideration of an audit.

There are several reasons for considering an audit to collect data in this case. Many innovation audits have a natural focus on the developmental phases (Hallgren, 2009), and here it is anticipated that the development of RE solutions will go through specific phases. Many audits have an underlying process model which may indicate the degree to which the constituent processes are systematic in implementation. Again, it is of interest to have a means to generate evidence of a systematic approach. There are some candidates for consideration.

Innovation management models or tools be used as a basis for a generic set of innovation management measurement areas to act as a framework for balanced measurement (Adams et al., 2006). Hallgren (2009) critiqued existing innovation audits in an attempt to propose an approach suited to improving high-involvement innovation. Nilsson and Ritzén (2014) identified 'illustrative examples' of innovation management models. They noted that "although these frameworks differ in their design and content, some commonalities exist around key enablers based on studies in highly innovative companies".

Singularly common among the models reviewed in the above three studies is that by Chiesa et al. (1996). The model presents the managerial processes and organisational mechanisms through which innovation is carried out. Underlying this model is the proposition that innovation success depends, in part, upon good practice in relevant management processes. 
The model identifies core and enabling processes, the outcome from which is innovation performance. Adams et al. (2006) noted that this tool overlaid core processes of innovation with a set of enabling processes applicable to 'hard' innovations. It facilitated evaluation of resource provision, leadership and the use of systems and tools. The process audit focuses on the degree to which best practice innovation sub-processes are implemented effectively. The process audit is complemented by a performance audit to focus on the outcomes of innovation processes and the impact on competitiveness. Chiesa et al. (1996) developed this audit for application in all manufacturing firms. In testing of the audit, they explored the usefulness and usability in these firms, categorised by Pavitt (1991) according to technological trajectory. One of these categories was "specialised supplier" engaged in key strategic task of finding and maintaining a specific niche. This audit has been used in subsequent research (de Weerd-Nederhof and Fisscher, 2003, Yam et al., 2004, Hallgren, 2009, Nilsson and Ritzén, 2014). Finally, this audit has been used as a basis for 400+ major field project by undergraduate students "to support, in so far as is realistic, the process of organizational and strategic development in the firms in which projects are undertaken" (Coughlan and Graham, 2009).

We selected and adapted the Chiesa et al. (1996) model to fit with a focus on innovation management in NT as a specialised supplier for delivering low-carbon energy, as illustrated in Figure 2. The five core processes are as follows:

- Idea generation concerns identifying user needs and matching them with technological capabilities to explore new or to enhance existing low-carbon energy systems.

- System development concerns how new low-carbon energy concepts are taken from development through to launch.

- Process innovation includes generating, implementing and improving low-carbon energy through energy delivery innovations.

- Market focus concerns monitoring and linking user and community expectations; planning and communicating with users and communities, and measuring performance.

- Finally, technology acquisition involves monitoring, selecting and acquiring lowcarbon energy technologies, developing new or improved technologies, and exploiting technical knowledge.

These core processes of innovation are enabled by the following:

- Leadership concerns how management sets innovation goals and priorities, champions the organisational efforts to achieve 'best practice', sets and maintains a climate for innovation.

- Through resourcing, management ensures that sufficient, appropriate organisational and financial resources are available.

- Through use of appropriate systems and tools, there is support for the innovation process and communication between those involved.

Finally, the core and enabling processes result in innovation performance, which in turn leads to low-carbon energy through hydropower as a source of RE.

\section{Innovation scorecard}

Based on the work by Voss et al. (1993) and adopted by Chiesa et al. (1996), an innovation audit was undertaken. Consisting of innovation self-assessment scorecards, the audit included the provision of supporting evidence and examples of changes in the NT that may have 
impacted the scorecard results. The scorecards distinguished among four levels of practice in each process area, consistent with the following characterisations:

- innovation is not managed or encouraged,

- basic procedures, management and motivation are in place,

- innovation is managed and encouraged as a key objective for the firm,

- 'world class' innovation performance.

In total, three NT staff contributed towards the data collection process for this paper. Two senior NT Wales Environmental Advisors were the key informants, while a third NT staff member (a Senior Project Manager) provided further archival data as supporting evidence of innovation management for the RE projects.

The two Environmental Advisors had worked with NT Wales part of the organisation since before 2010. These informants from NT Wales represents a region, i.e. Wales, of NT's work across the UK, and from here onwards both 'NT' and 'NT Wales' are used either in relation the organisational or regional evidence discussion, respectively. They were closely involved in facilitating the organisation to innovate in meeting its sustainability goals, developing different RE projects including the HP installations examined in this study. They provided prime sources of data: completing a self-audit using the innovation scorecards; providing semi-structured interviews and organisational reports; and, through several follow-up communications, clarifying or providing missing information. The range of data sources provided insights into the broader low-carbon energy goal for the NT and the specific role of HP projects in supporting this objective. As a set, the scorecards provided an overview of the NT's strengths and weaknesses in innovation management. The semi-structured interviews identified the characteristics and performance of these processes.

The innovation self-audit was used to capture the performance of NT Wales over a five-year period. The results provided by the two Environmental Advisors included (i) retrospective baseline scores were provided for 2010, a milestone year for the NT when it published its first low-carbon energy report (NT, 2010); and (ii) contemporary 2015 scores demonstrated the role innovation played in delivering organisational low-carbon energy.

The interview protocol was based upon the self-assessment scorecards, which provided a framework to understand the project practice and performance in relation to best practice. A variety of RE project-related documents provided background and corroborating details to prepare for the semi-structured interviews, which took place on-site in Wales to gather information specifically related to the growing low-carbon energy portfolio, and specifically the HP projects installed by NT Wales. This field component to the research enabled a broader appreciation of the physical context in which the HP projects were located.

Interview notes were typed up immediately to maximise recall, and it facilitated follow-up communications to fill data gaps from the interviews. One of the two NT advisors subsequently provided additional documentary data in relation to themes emerging during the interview.

\section{CASE OVERVIEW}

The National Trust

The National Trust (NT) is the largest landowner in the UK with responsibility of managing approximately 250,000 hectares. The organisation characterises itself as a conservation charity. As such, the NT is responsible for protecting heritage sites and areas of 'outstanding 
natural beauty' across the country (NT, 2016). This responsibility requires substantial energy requirements. They are shifting away from fossil fuel sources of heat and power for the hundreds of historic buildings that they manage and maintain which costs several million each year (NT, 2016). In 2010, the NT 'grow your own' energy report set targets to reduce energy demands by $50 \%$ by 2020 (NT, 2010). This strategy was established to secure the future vision 'For ever, for everyone.' Subsequently, the NT has delivered low-carbon energy innovations, including the development of an impressive RE portfolio (Blades, 2009).

\section{Developing HP projects}

As part of the overall NT low-carbon energy strategy, NT Wales constructed three HP projects between 2011 and 2015, each of which were examined as RE case studies for this research (Figure 3). Overlaps in the development of these HP projects are evident. They provide a means of local low-carbon energy for two neighbouring NT Wales farms.

The three case studies were: the $650 \mathrm{~kW}$ Hafod y Llan hydro (HP.1) and the $17 \mathrm{~kW}$ Gorsen hydro (HP.2) at the Hafod y Llan farm; and the $100 \mathrm{~kW}$ Hafod y Porth hydro (HP.3) on the nearby Hafod y Porth farm. The three projects were constructed in Snowdonia, a national park in north Wales. Despite differences in installation sizes and the specific stakeholders involved in each project, several key individuals were involved in at least two of the three projects.

The $650 \mathrm{~kW}$ HP.1 installation was the largest HP project undertaken by NT Wales. Located at the Hafod y Llan farm, the HP installation was constructed on the Afon (river) Cwm Llan (a sterile river in a copper mining area). It has been in operation since April 2014, with a 2.0 GWh per annum capacity. The challenges associated with this project included the remote location of the weir, situating the powerhouse, and minimising the environmental impacts during construction. Identifying contractors and suppliers, and processing licences and planning delayed the project feasibility review.

The small $17 \mathrm{~kW}$ HP. 2 project was also located on the Hafod y Llan farm. This project saw the reintroduction of a HP turbine in the Gorsen stream (the first installation dated back to 1892). It now generates 45-50 MWh per year and, as it was a small-scale project, a single company acted as contractor and turbine provider. The contractor provided a low-cost microHP system, utilised the original weir and constructed a basic powerhouse. The construction process was relatively fast due to the simpler design, however delays due to gaining a grid connection delayed the project.

Lastly, the $100 \mathrm{~kW}$ HP.3 project was located on the Afon y Cwm (river) at the nearby Hafod y Porth farm. The installation has been operational since October 2014, generating 400-500 MWh per annum. This installation followed the others as one of the REI pilot projects. The project was delivered much faster than its predecessors as innovative construction and turbine concepts were applied from what was learned from the previous HP projects. The feasibility and grid connection stages of the project were streamlined, and project construction progressed without delay, making HP.3 cost effective at its scale.

\section{CASE ANALYSIS}

Using the innovation scorecards, the performance of NT Wales is examined. Throughout, the attribution of this performance is generally to National Trust, within which NT Wales operates. The scorecards capture the innovation processes, enablers and outcomes. They also provide evidence from a range of energy saving strategies as well as RE development, with a 
specific focus on HP installations. Scorecard results were combined from the scores provided by the two senior environmental advisors. The results presented in Figure 4 include the range of results in each category pre-2010 and 2015. In all process areas, the 2015 scores exceeded those for 2010, evidence of a system-wide improvement in innovation management. The discussion in each section analyses the stimuli for these improvements.

\section{Core Processes of innovation}

Idea generation

Historically in the NT, innovation has been a driver for achieving low-carbon energy. Improvements were evident in the scores for all three sub-processes (from a 1-2 to a 2-3 range) relating to idea generation for reducing energy use. The improvements demonstrated the success of the NT in generating new concepts for different technologies with external stakeholders (e.g. marine source heat pump, HP, solar PV, LED lighting). The driver for inventiveness and creativity included NT staff being "given the freedom to follow an idea". A marginal improvement in planning also occurred, but this improvement was limited due to restrictions in risk taking. Risk was overcome through co-generating design concepts and codeveloping products, where the developer accepted the associated risk. The NT also built a trust-based working relationship with HP providers over multiple projects: the same turbine manufacturers in HP.2 and HP.3; and same contractors in HP.1 and HP.3.

\section{System development}

Based on the RE ideas co-generated in HP.1 and HP.2 that related to eco-design concepts being incorporated into the design of HP.3, the delivery and implementation of a modular turbine and precast concrete weir sections were evident in the final installation. This success was built on teamwork and organisation between the NT and HP developers and is reflected in a shift in scorecard results from a 1-3 to 3-4 range, with improvements in all related subprocesses. These innovations helped reduce project costs and accelerate the construction process. By adopting a stage-gate-like project management framework (PMF) (Figure 5) "much more rigour" was ensured and helped to minimise risk for the NT. However, the PMF restricted direct innovation investment as the "process sometimes [became] increasingly onerous". Fortunately, the NT staff worked closely with manufacturers and contractors, to allow them to share ownership of component development and this "has now become the norm". The PMF structure in place in the NT and the space for open innovation between all the stakeholders was fundamental to the freedom for design driven innovation to take place and for eco-design considerations to be included in HP.3.

\section{Innovation in delivery}

Delivering process innovation between 2010 and 2015 to reduce energy use was evident. The effectiveness in implementation of these innovations and continuous improvement is notable scorecard range increases from 1-3 to 3-4. The implementation of RE technologies accounted for a small part of project delivery process (e.g. "marine source heat pump delivery in 12 weeks, after 3 years of planning”). However, experience allowed for subsequent management of multiple RE projects simultaneously.

As the NT gained experience for HP installations, the process of innovation helped deliver faster and cheaper HP projects and managing innovation became simpler. Co-developing the modular turbine and precast concrete sections from concept to reality took time initially, and 
the benefit was realised in HP.3 based on the working relationship developed from the prior projects. Furthermore, that relationship, the organisational structure and the PMF that developed for managing these HP projects allowed the NT to reflect systematically on previous experiences and, so, improve continuously.

\section{Acquisition of technology}

NT expanded its network for collaboration as reflected in the improvements from 1-3 to 2-4 range scores. Over the five years, delivering low-carbon energy and low-carbon solutions became key objectives for the organisation. The experienced NT staff connected with "trade bodies and $R \& D$ groups" leading to the notable improvements in sourcing technologies. Improvements in the NT's strategy for acquiring technology was "based on need" and creating a suitable environment in the organisation for technology acquisition through "more collaboration" and "open source" solutions helped the NT to gain momentum in achieving low-carbon energy.

The role of the NT's environmental advisors included networking, developing links and collaboration. This role was evident through the collaboration in the turbine selection and design for HP.3. In addition, the openness of the NT with external organisations in delivering the HP projects led to a modular, low-carbon design - an eco-design approach to turbine system design - presented financial and environmental benefits. Eco-design was evident for HP. 2 and HP. 3 as modular and low-cost turbines were selected. In addition, the use of a precast concrete weir also provided cost savings, minimised waste material and reduced environmental pollution risks in the river. The use of local materials - wood and slate - and hiring local product manufacturers and contractors minimised the project transport emissions footprint. A modular turbine design introduced flexibility for future system maintenance and retrofits, as well as an allowance for cost-effective remanufacturing and refurbishment of components e.g. turbine runner blades. The success of the HP projects as part of a larger REI programme, and delivering them in an environmentally conscious manner, led to a shift from the NT sourcing of new technology to fit their needs to external providers presenting suitable technologies to the NT.

\section{Market focus}

NT focused on maintaining the link with 'growing that nation's love with special places'. The most significant positive improvement made by the NT was in market analysis and monitoring, with score ranges increasing from 1-2 to 2-4. They focused on understanding membership views of energy from "AGM questions on energy for the last 5 years". This focus demonstrates the NT's perception of its importance to the community. Further communication initiatives were evident through their award-winning blog and dedicated "communications and benefits team for energy work". This had a knock-on benefit in reaching visitors and members and relevance to visitors and members: NT "share as they learn" while maintaining their core objective to "grow the nation's love with special places". The three HP installations have been well documented and openly shared by the NT. To understand the impact, the NT analysed readership of the blogs and other social media outlets, leading to national broadcasts for HP.1. The evidence indicates that members and visitors support the direction the NT has taken since 2010, including the HP projects, as they understand the goal of low-carbon energy even for a conservation charity. 


\section{Enablers}

Leadership

The introduction of low-carbon energy as a priority for the NT has driven a significant change in the climate and the leadership processes for achieving innovation. This is evident in the scorecard results increasing from 1-2 to 1-4 ranges. NT is aware of innovation and, through active collaborations, is "allowing innovation to flourish" with the "support of trustees, executive teams and regional management". Within the NT, processes relating to leadership "have become much more structured", which provides distinct staff roles in NT and allows more scope for innovation. Improvements in innovation goals have been less evident as the focus of the NT remains on conservation. However, a "better understanding" of this focus has been achieved.

The success of the three HP installations has been driven by leaders in the NT who opened the doors to innovation through collaboration to achieve low-carbon energy. The expansion and creation of NT teams to deal specifically with this challenge, and the systems put in place (e.g. PMF) provided structured support for RE projects. In the event, natural leaders emerged within the NT and the willingness of the organisation to trust in these staff members led to support for innovation adoption in achieving the low-carbon energy goal.

\section{Resourcing}

Of all categories, enabling resources for innovation in the NT demonstrated only a negligible improvement for human resources and funding evident in the scorecard results from a 1-2 to a 1-3 between pre-2010 and 2015 ranges. However, as a conservation charity, resourcing innovation is being achieved through co-development with external organisations so enabling the NT "to stick to the basics". This emphasis reflects how the organisation pitches for funding: aligning its emphasis "with the wider charity aims and purpose" where innovation is not the goal but "can be a part of that goal".

\section{Systems and tools}

The NT monitored quality assurance using ISO14001 and has led to a scorecard improvement from a 1-3 to 2-4 range. However, the "measurement of quality is not really seen in terms of energy development" and performance improvements are only captured in relation to the entire NT. Current "performance indicators" may not capture innovation in the systems and tools adopted by the NT. Tools to share information across the NT have led to small improvements for the organisation. The systems in place focus on training "upskilling of staff, sharing the good and bad lessons" and this suggests a recognition that NT staff enable progress.

The use of the HP projects for training purposes was evident both in the NT and for external organisations. In addition, the tools and systems in place at the NT were shared openly with others to help develop HP installations. The role of the PMF was also to act as a tool to gather this information, while simultaneously providing quality assurance during the stages of project development.

\section{Outcome}

\section{Impact statement}

For the NT, the organisation has moved forward since 2010 for measurement and goals and innovation performance with scorecards ranges improving from 1-2 to 2-3 for each sub- 
process. In the words of the NT, to achieve low-carbon energy "the goals are kept simple". Innovation has played a role in achieving this goal for the NT "however it is not the measure". The impact made by the NT through delivering the range of low-carbon energy strategies translated as a 37\% reduction in baseline energy demands and generating $53 \%$ of this demand through RE sources: an impressive feat in five years.

Low-carbon energy on the two farms in north Wales were delivered through the development of the three HP projects outlined in this paper. They complement other RE technologies at these sites to provide a better mix of RE sources and reduce the demand for grid electricity. In relation to their impact, their ability to generate electricity meets the project goal and their continued generation provides a measure of their success. Designdriven innovation is evident in how the HP projects were delivered, as eco-design was incorporated into the development of HP.3 based on learning from earlier projects, through a space for open innovation and system development. Yet to the NT community, the capacity to generate electricity is presented as the headline for the projects.

\section{DISCUSSION}

This paper explores the primary research question: how has a systematic approach to the management of innovation aided in the delivery of low-carbon energy through RE projects? The empirical focus has been on three HP projects in the NT, a conservation charity. These projects aim to reduce future risks associated with increasing energy prices and enabling the NT to continue serving its main function i.e. conservation. Towards a response to this question, we revisit the evidence of delivery of hydropower through the adoption of ecodesign. We then reflect on the evidence of engagement in open or closed innovation, of being pulled by user requirements or to be pushed by a vision about possible product meanings, and of being increasingly systematic in design.

\section{Open or closed innovation}

NTW exhibited clear characteristics of an open model: both internal and external ideas and capabilities were of use (Chesbrough, 2003).

- Internally, the commitment of the NT to invest a further $£ 30$ million in RE projects (NT, 2015a) demonstrates its continuing belief in low-carbon energy. However, this success has only been achieved through a level of trust from board members in their energy team i.e. trust within the NT (Gundry et al., 2016). This trust has built up through the delivery of RE and energy saving projects on time, within budget and with evident support of the NT community (staff and the public). This has led to the growth of the RE team with dedicated roles to help support sustainability goals in the organisation.

- Externally, public support is particularly evident in the improving market focus, as the NT has increased feedback to board members and dissemination of its experiences in delivering RE projects to the general public. Furthermore, the sharpness of this market focus improvement is based upon analysis and monitoring, and a better understanding of its energy demands and performance.

- Externally, the NT adopted innovative construction techniques in the form of ecodesign solutions, such as low-cost, modular turbines, in turn achieving low-carbon installations. The NT approached this niche innovation in a unique, yet strategic manner: few improvements occurred internally within the NT regime with regards 
resources, funding and systems for delivering low-carbon energy measures. Rather, the successful delivery of ideas for innovations, developed within the NT between 2010 and 2015, was due to new external collaboration and sourcing of innovative, eco-design driven technology from elsewhere in the regime informed from the landscape. This approach reduced the risk associated with the projects and demonstrated how the organisation adopted a strategic niche management structure (Schot and Geels, 2007), to ensure innovation was incorporated in the process but did not inhibit the successful development of the HP installations.

These achievements extend the model of trust within organisations, proposed by Gundry et al. (2016) to include external organisations.

\section{Design driven innovation}

For National Trust, protecting the environment is a strategic priority that comes with a price tag estimated at $£ 103$ million in 2014/15 (NT, 2015b). The 2010 Energy: Grow Your Own report promoted an ambitious 2020 target of 50\% reduction in fossil fuel use for the NT, and this is evident through the three cases presented (NT, 2010). The cases show how front-line staff have supported innovation in low-carbon energy, while achieving innovation through adopting eco-design measures in project delivery, under a programme which was reinforced by top-down investment. This is particularly evident in the design considerations for HP.3 which was informed by learning from the two previous HP projects. This demonstrated design driven innovation which has reduced the environmental burdens associated with the installation. In summary, these measures included:

- Modular turbines: providing a low-cost design which reduces raw materials demands.

- Pre-cast concrete weir and intake sections: faster installation in ecologically-sensitive site. It can reduce the quantity of waste materials in comparison to in-situ casting.

- Wooden powerhouse structure: using an alternative and abundant low-carbon material for the powerhouse building reduces the environmental footprint of the structure. It allows for much faster construction, and due to its lighter loading requires a smaller foundation, saving concrete requirements for the building.

- Local slate roof as opposed to aluminium sheets: using local materials reduces transport demands for materials and replacement of aluminium with slate reduces the total environmental burdens of the powerhouse structure.

As with Verganti (2008), this innovation at the NT was "pushed by a firm's vision about possible new product meanings and languages that could diffuse in society". In design-driven innovation, the innovation starts "from the comprehension of subtle and unspoken dynamics in sociocultural models and results in proposing radically new meanings and languages that often imply a change in sociocultural regimes". To manage such an innovative approach the NT developed and applied its capability to understand, anticipate, propose, and influence the emergence of a new meanings for the innovative technology: it was promoted to the public and broader stakeholder base as a commitment to low-carbon energy. The process by which this new design driven innovation evolved, in the form of incorporating eco-design solutions in the development of the HP installations, involved a network of suppliers who appreciated and contributed to the action to influence the transitioning of the NT to a low-carbon community. In addition to innovation management, this study provides evidence of multi- 
level protected spaces, rules for further development of RE technology, and landscapes (Rip, 2012) in a conservation charity.

\section{More or less systematic}

The RE projects fit both with the operational needs of the NT and with the public perception of its responsibility. The projects are part of the low-carbon energy measures being implemented systematically on the NT properties across the UK. This approach fits with the market focus of the organisation and ensures that finances can be directed towards conservation, the main priority of the NT. The collaboration between HP stakeholders and iterative learning managed by the NT stage-gate approach to project development, allowed for eco-design considerations to achieve design driven innovation in these projects.

Analysis and monitoring has informed the support from Trust board and regular members for this prioritisation. So, innovating for low-carbon energy in the NT has been enabled through more effective leadership and has been supported through systematic processes and a more suitable climate. Furthermore, introducing a low-carbon energy strategy has clarified the market focus, and innovation has flourished to meet these needs while more systematic analysis and monitoring has ensured a better understanding and reporting of energy demands. In addition, the collection of energy use data validates the move towards systematic impact evaluation of the transition to a low-carbon community.

\section{CONCLUSIONS}

Delivering innovation to achieve low-carbon energy is perceived as a priority for many organisations. The construction of RE projects, such as hydropower installations, are part of a renewable energy investment programme at the National Trust, a conservation charity, advancing it on its journey a low-carbon community. This study applies and extends the conceptualisation of an innovation journey (Rip, 2012) to the conservation charity space. Here, in its niche, the conservation charity undertakes innovation for low-carbon energy projects in the form of hydropower installations. The charity is characterised by its mission, stakeholders and profile. In collaboration with its stakeholders, the systematic use by the conservation charity of open innovation and design-driven innovation to deliver eco-design through its projects defines the niche and regime through which the innovation journey is undertaken. As evident by the third hydropower installation, eco-design reduced the time taken to deliver the project and flexibility in future operation and maintenance was considered in its design, which translates as economic and environmental savings for the organisation (Gallagher et al., 2015). Finally, the realisation of low-carbon energy is against 'the slowly-changing backdrop...' (or landscape) '....against which interactions are played out' (Rip, 2012) and delivers renewable and low-carbon energy outcomes. The National Trust has expanded its renewable energy delivery team in recent years. Revisiting and expanding the niche over an extended time span and against the continually changing landscape will provide further insights into the development and diffusion of the regime.

\section{REFERENCES}

Adams, R., Bessant, J. \& Phelps, R. 2006. Innovation management measurement: A review. International Journal of Management Reviews, 8, 21-47.

Blades, N. 2009. The National Trust's approach to energy efficiency in historic buildings. National Trust. 
Bódis, K., Monforti, F. \& Szabó, S. 2014. Could Europe have more mini hydro sites? A suitability analysis based on continentally harmonized geographical and hydrological data. Renewable and Sustainable Energy Reviews, 37, 794-808.

Chesbrough, H. W. 2003. Open Innovation: The New Imperative for Creating and Profiting from Technology, Harvard Business School Press.

Chiesa, V., Coughlan, P. \& Voss, C. A. 1996. Development of a technical innovation audit. Journal of Product Innovation Management, 13, 105-136.

Coughlan, P. \& Graham, A. 2009. Embedding a Threshold Concept in Teaching and Learning of Product Development Management. Creativity and Innovation Management, 18, 190-198.

Croft, T. A. 2004. Conservation charity land ownership in Scotland. Scottish Geographical Journal, $120,71-82$.

de Weerd-Nederhof, P. \& Fisscher, O. 2003. Alignment and Alliances for Research Institutes Engaged in Product Innovation. Two Case Studies. Creativity and Innovation Management, $12,65-75$.

DECC 2016. Renewable Energy in 2015. Department of Energy \& Climate Change.

Docherty, M. 2006. Primer on "open innovation:" Principles and practice. The next "big thing" in innovation. PDMA Visions. PDMA.

EC 2009. Directive 2009/125/EC of 21 October 2009 establishing a framework for the setting of ecodesign requirements for energy-related products. Official Journal of the European Union.

EC 2015. Ecodesign legislation. 6.1.2015 ed.: European Commission.

EUREC 2009. Research Priorities for Renewable Energy Technology by 2020 and Beyond. Brussels: EUREC.

Fernandes, A. A., Da Silva Vieira, S., Medeiros, A. P. \& Natal Jorge, R. M. 2009. Structured Methods of New Product Development and Creativity Management: A Teaching Experience. Creativity and Innovation Management, 18, 160-175.

Freeman, R. E. 1994. The Politics of Stakeholder Theory: Some Future Directions. Business Ethics Quarterly, 4, 409-421.

Gallagher, J., Basu, B., Browne, M., Kenna, A., McCormack, S. J., Pilla, F. \& Styles, D. 2018. Adapting Stand-Alone Renewable Energy Technologies for the Circular Economy through Eco-Design and Recycling. Journal of Industrial Ecology.

Gallagher, J., Styles, D., McNabola, A. \& Williams, A. P. 2015. Current and future environmental balance of small-scale run-of-river hydropower. Environ Sci Technol, 40, 6344-6351.

Gebauer, H. \& Saul, C. J. 2014. Business model innovation in the water sector in developing countries. Science of The Total Environment, 488-489, 512-520.

Grönlund, J., Sjödin, D. R. \& Frishammar, J. 2010. Open Innovation and the Stage-Gate Process: A Revised Model for New Product Development. California Management Review, 52, 106-131.

Gundry, L. K., Muñoz-Fernandez, A., Ofstein, L. F. \& Ortega-Egea, T. 2016. Innovating in Organizations: A Model of Climate Components Facilitating the Creation of New Value. Creativity and Innovation Management, 25, 223-238.

Hallgren, E. W. 2009. How to Use an Innovation Audit as a Learning Tool: A Case Study of Enhancing High-Involvement Innovation. Creativity and Innovation Management, 18, 48-58.

Heiskanen, E., Jalas, M., Rinkinen, J. \& Tainio, P. 2015. The local community as a "low-carbon lab": Promises and perils. Environmental Innovation and Societal Transitions, 14, 149-164.

Hertwich, E. G., Gibon, T., Bouman, E. A., Arvesen, A., Suh, S., Heath, G. A., Bergesen, J. D., Ramirez, A., Vega, M. I. \& Shi, L. 2015. Integrated life-cycle assessment of electricitysupply scenarios confirms global environmental benefit of low-carbon technologies. Proceedings of the National Academy of Sciences, 112, 6277-6282.

IEA 2012. Technology Roadmap: Hydropower. Paris: International Energy Agency.

IRENA 2015. Renewable Power Generation Costs in 2014. International Renewable Energy Agency.

IRENA 2016. Roadmap for a Renewable Energy Future. 2016 Edition ed.: International Renewable Energy Agency.

Jabbour, C. J. C., Neto, A. S., Gobbo Jr, J. A., Ribeiro, M. d. S. \& Jabbour, A. B. L. d. S. 2015. "Ecoinnovations in more sustainable supply chains for a low-carbon economy: A multiple case study of human critical success factors in Brazilian leading companies". International Journal of Production Economics, 164, 245-257. 
Jiang, P., Chen, Y., Xu, B., Dong, W. \& Kennedy, E. 2013. Building low carbon communities in China: The role of individual's behaviour change and engagement. Energy Policy, 60, 611620.

Kleijn, R., van der Voet, E., Kramer, G. J., van Oers, L. \& van der Giesen, C. 2011. Metal requirements of low-carbon power generation. Energy, 36, 5640-5648.

Klewitz, J. \& Hansen, E. G. 2014. Sustainability-oriented innovation of SMEs: a systematic review. Journal of Cleaner Production, 65, 57-75.

Kumar, A., Schei, T., Ahenkorah, A., Caceres Rodriguez, R., Devernay, J. M., Freitas, M., Hall, D., Killingtveit, A. \& Liu, Z. 2011. Hydropower. In: EDENHOFER, O., PICHS-MADRUGA, R., SOKONA, Y., SEYBOTH, K., MATSCHOSS, P., KADNER, S., ZWICKEL, T., EICKEMEIER, P., HANSEN, G., SCHLÖMER, S. \& STECHOW, C. V. (eds.) In IPCC Special Report on Renewable Energy Sources and Climate Change Mitigation. Cambridge,

United Kingdom and New York, NY, USA: Cambridge University Press.

Leenders, R. T. A. J., Van Engelen, J. M. L. \& Kratzer, J. 2007. Systematic Design Methods and the Creative Performance of New Product Teams: Do They Contradict or Complement Each Other? Journal of Product Innovation Management, 24, 166-179.

Leonard-Barton, D. 1990. A Dual Methodology for Case Studies: Synergistic Use of a Longitudinal Single Site with Replicated Multiple Sites. Organization Science, 1, 248-266.

Markides, C. 1997. Strategic Innovation. Sloan Management Review, 9-23.

Middlemiss, L. \& Parrish, B. D. 2010. Building capacity for low-carbon communities: The role of grassroots initiatives. Energy Policy, 38, 7559-7566.

Molle, F., Jaykody, P., Ariyaratne, R. \& Somatilake, H. S. 2005. Balancing irrigation and hydropower: case study from southern Sri Lanka. Research Report 94. Colombo, Sri Lanka: International Water Management Institute (IWMI).

Moloney, S., Horne, R. E. \& Fien, J. 2010. Transitioning to low carbon communities-from behaviour change to systemic change: Lessons from Australia. Energy Policy, 38, 7614-7623.

Nilsson, S. \& Ritzén, S. 2014. Exploring the Use of Innovation Performance Measurement to Build Innovation Capability in a Medical Device Company. Creativity and Innovation Management, 23, 183-198.

NT 2010. Energy - Grow your own. National Trust.

NT 2014a. Forecast? - Changeable! Some examples of Climate Change Impacts around the National Trust. National Trust.

NT 2014b. National Trust Annual Report 2013/14. National Trust.

NT. 2015a. £30 million investment in a sustainable future [Online]. National Trust. Available: www.nationaltrust.org.uk/news/30-million-investment-in-a-sustainable-future [Accessed January 2016].

NT 2015b. National Trust Annual Report 2014/15. National Trust.

NT 2016. National Trust Annual Report 2015/16. National Trust.

Ollila, S. \& Elmquist, M. 2011. Managing Open Innovation: Exploring Challenges at the Interfaces of an Open Innovation Arena. Creativity and Innovation Management, 20, 273-283.

Reilly, J. 2013. Achieving a low-carbon society. Climate Policy, 13, 155-158.

REN21 2014. Renewables 2014 Global Status Report. ISBN 978-3-9815934-2-6 ed. Paris.

Rip, A. 2012. The Context of Innovation Journeys. Creativity and Innovation Management, 21, 158170.

Rogers, E. M. 1995. Diffusion of innovations, New York, Free Press.

Santolaria, M., Oliver-Solà, J., Gasol, C. M., Morales-Pinzón, T. \& Rieradevall, J. 2011. Eco-design in innovation driven companies: perception, predictions and the main drivers of integration. The Spanish example. Journal of Cleaner Production, 19, 1315-1323.

Schot, J. \& Geels, F. W. 2007. Niches in evolutionary theories of technical change. Journal of Evolutionary Economics, 17, 605-622.

Schot, J. \& Geels, F. W. 2008. Strategic niche management and sustainable innovation journeys: theory, findings, research agenda, and policy. Technology Analysis \& Strategic Management, 20, 537-554.

Shu-Yang, F., Freedman, B. \& Cote, R. 2004. Principles and practice of ecological design. Environmental Reviews, 12, 97-112.

Turner, R., Miller, G. \& Gilbert, D. 2001. The role of UK charities and the tourism industry. Tourism Management, 22, 463-472. 
UNFCCC 2015. COP21 Paris Agreement - Council on Foreign Relations. In: CHANGE, U. N. F. C. O. C. (ed.).

Verganti, R. 2008. Design, Meanings, and Radical Innovation: A Metamodel and a Research Agenda*. Journal of Product Innovation Management, 25, 436-456.

Voss, C. A. 2009. Case research in operations management. In: KARLSSON, C. (ed.) Researching Operations Management. Abingdon: Routledge.

Voss, C. A., Chiesa, V. \& Coughlan, P. 1993. Innovation, your move, self assessment guide and workbook, London, IDTI.

Yam, R. C. M., Guan, J. C., Pun, K. F. \& Tang, E. P. Y. 2004. An audit of technological innovation capabilities in chinese firms: some empirical findings in Beijing, China. Research Policy, 33, $1123-1140$.

Zhang, X., Shen, G. Q. P., Feng, J. \& Wu, Y. 2013. Delivering a low-carbon community in China: Technology vs. strategy? Habitat International, 37, 130-137. 